5-1-2002

\title{
Physiological and behavioral variation in estivation among mud turtles (Kinosternon spp.)
}

Day B. Ligon

Charles C. Peterson

Follow this and additional works at: https://bearworks.missouristate.edu/articles-cnas

\section{Recommended Citation}

Ligon, Day B., and Charles C. Peterson. "Physiological and behavioral variation in estivation among mud turtles (Kinosternon spp.)." Physiological and Biochemical Zoology 75, no. 3 (2002): 283-293.

This article or document was made available through BearWorks, the institutional repository of Missouri State University. The work contained in it may be protected by copyright and require permission of the copyright holder for reuse or redistribution.

For more information, please contact BearWorks@library.missouristate.edu. 


\section{Physiological and Behavioral Variation in Estivation among Mud Turtles (Kinosternon spp.)}

\author{
Day B. Ligon* \\ Charles C. Peterson \\ Department of Zoology, 430 Life Sciences West, Oklahoma \\ State University, Stillwater, Oklahoma 74078-3052
}

Accepted 4/9/02

\begin{abstract}
Kinosternid mud turtles, a primarily aquatic group, exhibit variable degrees of terrestrial activity in the Sonoran and Chihuahuan Deserts. We compared behavioral and physiological responses to dry conditions in four populations representing three species, Kinosternon sonoriense, Kinosternon flavescens, and Kinosternon hirtipes. All four groups were subjected to simulated dry season conditions in the laboratory, during which activity was monitored and physiological responses (blood chemistry and rates of resting metabolism and evaporative water loss) were measured. Kinosternon flavescens and K. hirtipes represented extremes in apparent ability to estivate, based on activity and rate of increase of plasma osmolality. Two populations of $K$. sonoriense exhibited intraspecific differences in behavioral and physiological measures that were related to extant environmental conditions. Large numbers of $K$. sonoriense from Arizona and $K$. hirtipes, the poorest estivators, had to be rehydrated after only $30 \mathrm{~d}$ out of water. Kinosteron flavescens had the lowest metabolic rates, but no evidence of metabolic depression during dehydration was found for any of the four populations. We conclude that the differences in capacity for estivation among populations are primarily linked to variable behavioral responses to dry conditions, though high rates of evaporative water loss in $K$. hirtipes represent a probable physiological constraint.
\end{abstract}

\section{Introduction}

The present-day deserts of southwestern North America were cool and wet during the Late Pleistocene (ca. 18,000 years ago) and dominated by coniferous forests (Schmidt 1979; Van De-

\footnotetext{
*Corresponding author; e-mail: lday@okstate.edu.
}

Physiological and Biochemical Zoology 75(3):283-293. 2002. (C) 2002 by The University of Chicago. All rights reserved. 1522-2152/2002/7503-1097\$15.00 vender et al. 1987). Desertification of the region began about 12,000 years ago (Van Devender et al. 1987; Fredrickson et al. 1998). The shift toward an increasingly arid climate undoubtedly had a profound impact on aquatic flora and fauna. Probably, many such organisms disappeared from the region; those that remained either became restricted to areas where permanent water persisted or possessed or evolved behavioral and physiological characteristics that facilitated survival in the drier conditions.

Three species of mud turtles (Kinosternidae) are indigenous to the Sonoran and Chihuahuan Deserts: the Sonoran mud turtle (Kinosternon sonoriense), the yellow mud turtle (Kinosternon flavescens), and the Mexican rough-footed mud turtle (Kinosternon hirtipes; Iverson 1992; Ernst et al. 1994). Though all three species inhabit areas where water is generally scarce and rainfall highly seasonal, behavioral responses to such conditions vary substantially among species (Ernst et al. 1994) and even among conspecific populations (Ligon 2001).

Kinosternon flavescens frequents temporary farm ponds in semiarid grasslands and deserts (Mahmoud 1969; Iverson 1989; Ernst et al. 1994) and has long been recognized as a champion estivator capable of surviving as long as $2 \mathrm{yr}$ without water (Rose 1980). During extended periods of estivation, yellow mud turtles become inactive and reportedly exhibit a decrease in metabolic rate (Seidel 1978). Kinosternon hirtipes, however, is highly aquatic, limiting its activity to permanent seeps and springs (Iverson et al. 1991; Ernst et al. 1994). In laboratory trials, $K$. hirtipes exhibited rates of evaporative water loss (EWL) nearly three times greater than $K$. flavescens and failed to become quiescent when placed on dry substrate (Seidel and Reynolds 1980).

The degree of drought tolerance in K. sonoriense appears to be highly variable. In general, they are reported to be aquatic, only occurring where water is available all year and rarely venturing onto land (Hulse 1974; Ernst et al. 1994; van Loben Sels et al. 1997). However, in the Peloncillo Mountains of New Mexico along the extreme eastern edge of their range, populations inhabit canyons where water is highly seasonal (Stone 2001), and turtles survive drought by estivating (Ligon 2001). The physiological response to dry conditions of New Mexico $K$. sonoriense was similar to that of $K$. flavescens (Peterson and Stone 2000).

Variable selective pressure for drought tolerance resulting from regional variation in water availability (both temporal and spatial) may account for the range of drought tolerance found among desert-dwelling kinosternids. Estivation is a behavior 
with profound physiological consequences (Peterson and Stone 2000). In populations where water availability is seasonally intermittent, the physiological rigors of prolonged terrestrial dormancy seem likely to select for a coadapted suite of behavioral and physiological traits that enhance drought survival (Christian et al. 1996). Examples of such traits include (1) quiescent and/or burrowing behavior during drought, (2) tolerance to loss of body water and concomitant increases in body fluid concentrations (anhomeostasis; Peterson 1996; Peterson and Stone 2000), (3) reduced rates of EWL (Chessman 1984), (4) reduced metabolic rate (Kennett and Christian 1994), and (5) storage of excretory wastes to minimize loss of water as a urinary solvent (Peterson and Stone 2000). An examination of interpopulational differences in these traits should determine whether differences in behavioral responses to drought by mud turtles in the desert Southwest are purely a function of water availability or are driven by physiological adaptations and constraints for terrestrial activity.

Our first objective was to compare physiological and behavioral responses to dry conditions by Sonoran mud turtles from two populations: one in which surface water is absent for part of the year and estivation by turtles has been documented (Ligon 2001) and one from an area where spring-fed streams hold water all year and $K$. sonoriense have been described as obligately aquatic (van Loben Sels et al. 1997). We also tested responses of $K$. flavescens and $K$. hirtipes to dry conditions to give meaningful context to differences observed among $K$. sonoriense and to more completely describe the range of physiological and behavioral responses to drought of all kinosternids indigenous to the arid southwestern United States.

\section{Material and Methods}

Animal Acquisition

Ten Kinosternon hirtipes were collected on May 17, 2000, from a permanent seep in Presidio County, Texas. Ten Kinosternon flavescens were collected on May 27, 2000, from an ephemeral cattle pond in Greer County, Oklahoma. Kinosternon sonoriense were collected from two populations, distinguished hereafter by their state of origin (Arizona and New Mexico). Ten turtles were collected on May 15, 2000, from a small spring in the Chiricahua Mountains, Coronado National Forest, Cochise County, Arizona. The second population was collected on May 13-14, 2000, from three sites within $5.5 \mathrm{~km}$ of each other in the Peloncillo Mountains, Coronado National Forest, Hidalgo County, New Mexico.

\section{Experimental Protocol}

All turtles were transported to Oklahoma State University within $5 \mathrm{~d}$ of capture and maintained until experiments began in June 2000. During this time, turtles were kept in $5-10 \mathrm{~cm}$ of deionized water at room temperature $\left(20.5^{\circ}-23.0^{\circ} \mathrm{C}\right)$ and fed super worms (Zophobas morio), crickets (Acheta domestica), and various thawed fish ad lib. Light was provided by incandescent and fluorescent sources and was set on a 16L : 8D cycle. Animals were maintained under Oklahoma State University Animal Care and Use Committee protocol 859.

Turtles were weighed and $300-500-\mu \mathrm{L}$ blood samples were drawn (see "Blood Samples") on June 21 and 22, following a 15- or 16-d fast. Resting metabolic rates (RMR) and EWL were measured on the afternoons of June 23-July 1. Following these measurements, turtles were placed in population-specific groups of three or four in opaque plastic tubs filled to $15 \mathrm{~cm}$ with dry vermiculite. All incandescent lights were turned off, but ambient light from overhead fluorescent fixtures was left on a $16 \mathrm{~L}: 8 \mathrm{D}$ cycle. Additional vermiculite was added to each tub as the substrate settled to maintain depths sufficient for the turtles to bury themselves completely.

Turtles were removed and weighed five times during estivation trials. In addition to pretrial measurements, blood samples were drawn on July 22 (day 31, midtrial), on August 15 (day 55, at the end of the trial), and on August 18 following replacement in water. EWL and RMR were measured at the end of the trial between August 10 and 15 and following rehydration between August 25 and 31.

\section{Behavior}

Each turtle's identification number was written on its carapace with a permanent marker so that identification was possible with minimal disturbance. Activity levels were scored on $37 \mathrm{~d}$ of the 55-d trial. Activities were scored as follows: $0=$ inactive (buried or on the surface with eyes closed), $1=$ sedentary on surface with eyes open, 2 = eyes open, moving around on surface. Individual scores were summed and then divided by the total number of observations to calculate each turtle's mean activity level for the entire trial.

\section{Body Mass}

Turtles were weighed at 7-16-d intervals throughout the trial. Turtles that lost $30 \%$ of maximum hydrated pretrial mass before the completion of the trial were returned to water. Reported desiccation limits for turtles are 30\%-35\% of hydrated mass (Ernst 1968; Minnich 1979; Mautz 1982; Peterson and Stone 2000).

\section{Blood Samples}

Blood was drawn on four occasions: immediately before removal from water, after $31 \mathrm{~d}$, at the end of the trial (55 d), and following rehydration. All samples were drawn from a sinus located dorsal to the seventh cervical vertebra (Kuchling 1999; Peterson and Greenshields 2001). Turtles could remain retracted into their shells, thereby reducing the stress caused by 
the procedure, and samples of adequate volume (300-500 $\mu \mathrm{L})$ could be drawn reliably, though dilution with lymph was common (such mixture of lymph with blood is likely to affect only protein and potassium levels; Crawshaw and Holz 1996).

Two to three heparinized capillary tubes were filled with blood and centrifuged; osmolality of the plasma fraction was measured with a Wescor vapor pressure osmometer. With the exception of the 31-d sample, the remaining blood was placed on ice in a heparinized microtainer and transported to the Oklahoma State University veterinary clinical pathology laboratory for additional analyses. Samples were analyzed for plasma concentrations of sodium, potassium, blood urea nitrogen (BUN), total protein, and circulating uric acid with a Kodak Ektachem 750 autoanalyzer. The 31-d blood samples were small $(<100 \mu \mathrm{L})$, and many contained lymph; the only measurement made was extracellular fluid (ECF) osmolality.

\section{Evaporative Water Loss}

Measurement of EWL followed methods described by Peterson and Stone (2000). Turtles were weighed (Acculab V-2000 balance, $\pm 0.1 \mathrm{~g}$ ) and then placed in plastic chambers (955 or $1,835 \mathrm{~mL}$ depending on turtle's size) between 1000 and 1045 hours on the days that EWL was to be measured. Each chamber was fitted with two stopcocks on opposing sides of the lid. The rim of each container was lined with Teflon tape before pressing the lid on to ensure an airtight fit. The containers were placed in an environmental chamber $\left(28^{\circ} \mathrm{C} \pm 0.5^{\circ} \mathrm{C}\right)$ with the stopcocks open, and a tubing manifold was connected to one stopcock on each chamber. Air was pumped from outside the building through a column of Drierite and then to each chamber. Turtles were left in the dark for $4-6.5 \mathrm{~h}$ to allow body temperatures to equilibrate.

Water collection columns were constructed by connecting two 3-cc syringe bodies in series. Each syringe was equipped with a stopcock and then filled with Drierite. With stopcocks closed, each column was weighed twice $( \pm 0.1 \mathrm{mg}$, Scientech analytical balance) before each trial, and the mean of the two measurements was used for the pretrial mass.

A drying column was attached to each turtle chamber, and dry air was pumped into the chambers and through the columns at $100 \mathrm{~mL} / \mathrm{min}$ (OMEGA mass flowmeter). EWL trials lasted $1.5-2.0 \mathrm{~h}$, after which columns were reweighed. The difference between pre- and posttrial mass was assumed to equal the volume of water lost from cutaneous and pulmonary surfaces. This technique yields highly repeatable results for mud turtles (Peterson and Stone 2000), and empirical simulations and statistical tests demonstrated that water recovery was efficient (mean $=98.9 \%$, compared with mass loss) and was not affected by chamber size. EWL trials were repeated the following day on two occasions when turtles urinated in their chambers.

\section{Metabolic Rate}

Methodology for measurement of metabolic rates was as described by Peterson and Stone (2000). RMR was measured as oxygen consumption by closed system respirometry (Vleck 1987). Metabolic trials were conducted at $28^{\circ} \pm 0.5^{\circ} \mathrm{C}$ and were initiated between 1608 and 1831 hours, ca. $0.5 \mathrm{~h}$ after EWL measurements.

The tubing manifold was disconnected, and the turtle chambers were carefully removed from the environmental chamber into a dimly lit room. With both stopcocks open, air samples were drawn into 20 -mL syringes equipped with stopcocks. The stopcocks on the syringe and chamber were then closed, the syringe removed, and the time of sampling recorded. Turtles in sealed chambers were returned to the dark environmental chamber and removed after 57 to $65 \mathrm{~min}$, when posttrial samples were drawn from a stopcock after pumping the syringe several times to ensure mixing.

Oxygen concentrations of all air samples were analyzed in 10-mL aliquots with a Sable Systems FC-1 oxygen analyzer. Air was drawn from outside the building at a regulated flow rate of $100 \mathrm{~mL} / \mathrm{min}$ and dried with a column of Drierite. Each aliquot was injected into the air stream, which passed through a small column of Drierite and Ascarite to remove water and carbon dioxide and then through the oxygen analyzer. Oxygen consumption for each turtle was calculated as the difference between the initial and final volumes of oxygen after correcting for chamber volume (Peterson 1990).

\section{Data Analysis}

Turtles from all populations were separated into two groups: those that remained without water for the duration of the 55$\mathrm{d}$ estivation trial (group A) and those that were rehydrated approximately midway through the trial due to rapid decreases in body mass (group B). With the exceptions of activity and plasma osmolality, only group A turtles were included in analyses. Plasma osmolality was analyzed for two data sets: one composed of only the full-trial estivators over the course of the entire trial and the second including pooled data for both groups over the first $30 \mathrm{~d}$ of estivation, before any turtles were returned to water. Activity levels were calculated for pooled data from both groups; mean activity levels for group A turtles only are also reported for comparison with other variables.

Because we obtained insufficient blood samples from a few turtles during one or more sampling periods, we were unable to apply a repeated measures analysis to the entire data set. Therefore, body mass, proportion of hydrated mass, and blood chemistry variables were analyzed using a two-way ANOVA (date and population as grouping variables) to test for differences among populations. All results were confirmed by repeated measures ANOVA on a data subset that permitted such analysis. Post hoc pair-wise comparisons were conducted using 


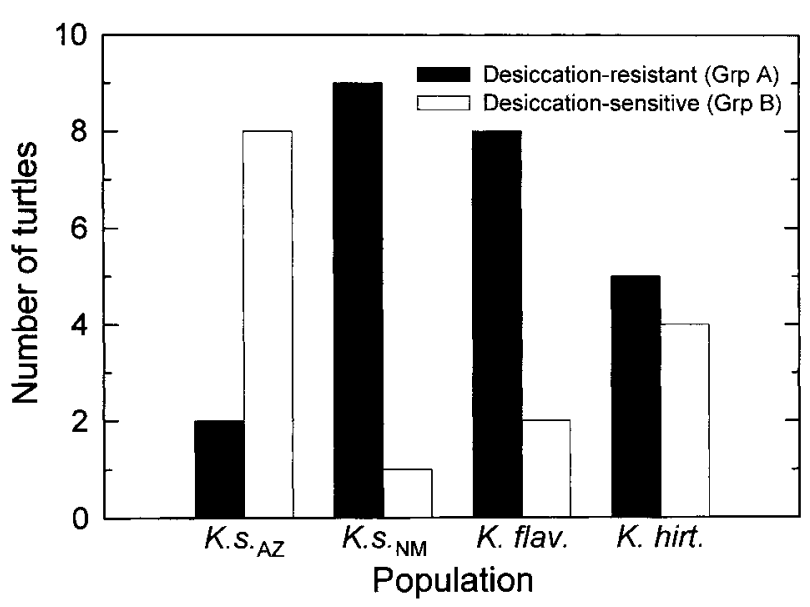

Figure 1. Grouping of mud turtles (Kinosternon spp.) according to rate of dehydration. Group A turtles (desiccation-resistant) completed the 55-d dehydration trial, and group B (desiccation-sensitive) turtles were rehydrated in $30 \mathrm{~d}$ after losing $\sim 30 \%$ of hydrated mass. K.s. $._{N M}=$ New Mexico Kinosternon sonoriense, K.s. ${ }_{A Z}=$ Arizona $K$. sonoriense, $K$. flav. $=$ Kinosternon flavescens, $K$. hirt. $=$ Kinosternon hirtipes.

the Student-Newman-Keuls method. RMR and EWL were analyzed using ANCOVA of log-transformed variables with log body mass as a covariate to control for the effects of body size.

Pearson correlations were calculated for a data set of individuals' mean rate of change for each variable during dehydration (the difference between end-of-trial and before-trial measurements divided by days elapsed) to look for effects of activity and dehydration on physiological responses to drought. Statistical procedures were performed using Excel, Sigmastat, or SYSTAT. Results are reported as mean \pm 1 SE.

\section{Results}

Grouping

Turtles were divided into two groups: those that completed the entire 55-d trial (group A) and those that were rehydrated after just 30-33 d (group B; Fig. 1). Group B was composed of eight Kinosternon sonoriense from Arizona, five Kinosternon hirtipes, two Kinosternon flavescens, and one $K$. sonoriense from New Mexico. Two turtles died during the trial: an Arizona K. sonoriense that lost $32 \%$ of hydrated body mass after $25 \mathrm{~d}$ out of water and a $K$. hirtipes that lost $29 \%$ of hydrated mass after 51 d. Another K. hirtipes that exhibited symptoms thought to be indicative of extreme dehydration was also removed from the study. Except where indicated, all results are based on group A turtles only.

\section{Behavior}

Activity levels ranged from very low (turtles that remained sedentary for the duration of the trial) to very high (frequent restless movement and attempts to escape). Early in the study, six turtles (five $K$. hirtipes and one K. sonoriense from Arizona) escaped from their tubs for a few hours, after which wire mesh lids were installed.

When turtles from groups A and B were pooled, K. flavescens exhibited the lowest levels of activity, whereas $K$. sonoriense from Arizona and $K$. hirtipes showed similar high levels of activity. Activity levels of $K$. sonoriense from New Mexico were intermediate to the two extremes (Fig. 2). The few Arizona K. sonoriense and $K$. hirtipes that remained out of water for the duration of the trial exhibited activity levels comparable with those of $K$. flavescens, much lower than averages for their populations (Fig. 2).

\section{Body Mass}

Kinosternon hirtipes were larger than turtles from the three other populations, yet patterns of mass loss, expressed relative to hydrated mass, did not differ among populations (Table 1; Fig. 3). Group A turtles lost an average of $0.38 \% \pm 0.03 \%$ body mass per day over $55 \mathrm{~d}$ without water. Group B turtles lost mass at a faster rate before rehydration $(0.49 \% \pm 0.12 \%$ per day during the first $30 \mathrm{~d}$ of the trial). There was a strong correlation between activity levels and relative mass loss but not absolute mass loss (Table 2).

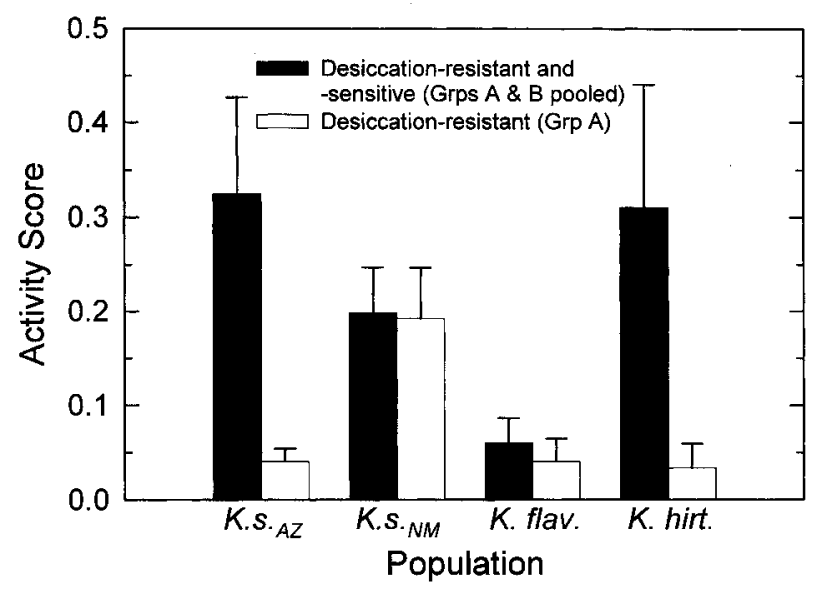

Figure 2. Mean activity levels of each mud turtle population (see text for calculation of activity scores). Black bars are pooled data for group A (desiccation-resistant) and group B (desiccation-sensitive) turtles; white bars represent activity levels of group A turtles only. Error bars are $\pm 1 \mathrm{SE}$. 
Table 1: ANOVA summary of responses of four populations of mud turtles to simulated dry season conditions

\begin{tabular}{|c|c|c|c|c|c|c|}
\hline Variable & $N$ & Date & Population & Date $\times$ Population & Date Effect & $\begin{array}{l}\text { Population } \\
\text { Effect }\end{array}$ \\
\hline Mass (g) & 95 & $1.99(3,79 ; .122)$ & $5.92(3,79 ; .001)$ & $.05(9,79 ; 1.000)$ & $\ldots$ & $\begin{array}{l}\text { K.h. }>\text { K.f. }= \\
K . s_{\cdot \mathrm{AZ}}=\text { K.s. } \cdot_{\mathrm{NM}}\end{array}$ \\
\hline \multicolumn{7}{|l|}{ Relative mass } \\
\hline (\% max.) & 95 & $147.78(3,79 ; .001)$ & $.10(3,79 ; .961)$ & $.48(9,79 ; .883)$ & $\mathrm{B}=\mathrm{R}>\mathrm{M}>\mathrm{E}$ & $\ldots$ \\
\hline \multicolumn{7}{|l|}{ Osmolality (mOsm): } \\
\hline Group $A^{a}$ & 89 & $38.52(3,73 ;<.001)$ & $2.04(3,73 ; .116)$ & $.29(9,73 ; .976)$ & $\mathrm{E}>\mathrm{M}>\mathrm{B}=\mathrm{R}$ & $\ldots$ \\
\hline Groups $\mathrm{A}$ and $\mathrm{B}^{\mathrm{b}}$ & 77 & $57.87(1,69 ;<.001)$ & $4.41(3,69 ; .007)$ & $2.74(3,69 ; .050)$ & $\mathrm{B}<\mathrm{M}$ & $\begin{array}{c}\text { K.s. } \cdot_{\mathrm{AZ}}>K \cdot s_{\cdot_{\mathrm{NM}}}= \\
\text { K.h. }=\text { K.f. }\end{array}$ \\
\hline Sodium (mmol/L) & 68 & $55.28(2,56 ;<.001)$ & $1.34(3,56 ; .269)$ & $.53(6,56 ; .786)$ & $\mathrm{E}>\mathrm{B}>\mathrm{R}$ & $\ldots$ \\
\hline \multicolumn{7}{|l|}{ Urea nitrogen } \\
\hline$(\mathrm{mg} / \mathrm{dL})$ & 68 & $101.79(2,56 ;<.001)$ & $2.43(3,56 ; .075)$ & $2.80(6,56 ; .019)^{\mathrm{c}}$ & $E>B=R$ & Interaction $^{c}$ \\
\hline Uric acid (mg/dL) & 68 & $13.18(2,56 ;<.001)$ & $.85(3,56 ; .472)$ & $.48(6,56 ; .821)$ & $E>B=R$ & $\ldots$ \\
\hline \multicolumn{7}{|l|}{ Potassium } \\
\hline$(\mathrm{mmol} / \mathrm{L})$ & 68 & $49.33(2,56 ;<.001)$ & $6.35(3,56 ; .001)$ & $6.46(6,56 ;<.001)^{d}$ & Interaction $^{\mathrm{d}}$ & $\begin{array}{c}K . s_{\cdot}{ }_{\mathrm{AZ}}>K . s_{\cdot \mathrm{NM}}> \\
K . f .>K . h .\end{array}$ \\
\hline Protein $(\mathrm{g} / \mathrm{dL})$ & 68 & $55.74(2,56 ;<.001)$ & $6.30(3,56 ; .001)$ & $6.94(6,56 ;<.001)^{\mathrm{e}}$ & Interaction $^{\mathrm{e}}$ & $\begin{array}{c}K . s_{\cdot_{\mathrm{AZ}}}>K . s_{\cdot_{\mathrm{NM}}}> \\
\text { K.f. }>\text { K.h. }\end{array}$ \\
\hline $\log \mathrm{EWL}^{\mathrm{f}}$ & 70 & $1.49(2,57 ; .234)$ & $8.49(3,57 ;<.001)$ & $.02(6,57 ; .423)$ & $\ldots$ & $\begin{array}{c}K . h .>K . s_{\cdot_{\mathrm{AZ}}}= \\
K . s_{\cdot_{\mathrm{NM}}}=K . f .\end{array}$ \\
\hline $\log \operatorname{RMR}^{\mathrm{f}}$ & 70 & $5.67(2,57 ; .006)$ & $11.95(3,57 ;<.001)$ & $1.58(6,57 ; .169)$ & $\mathrm{E}>\mathrm{B}=\mathrm{R}$ & $\begin{array}{l}K . f .<K . s_{\cdot \mathrm{AZ}}= \\
\quad K . s_{\cdot_{\mathrm{NM}}}=K . h .\end{array}$ \\
\hline
\end{tabular}

Note. Shown are $F$ values followed by degrees of freedom and $P$ values in parentheses. "Date Effect" and "Population Effect" columns show relationships among samples according to post hoc pair-wise comparisons by the Student-Newman-Keuls method on repeated measures for a data subset. B = before trial, $\mathrm{M}=$ midtrial, $\mathrm{E}=$ end of trial, and $\mathrm{R}=$ following rehydration. K.f. $=$ Kinosternon flavescens, K.h. $=K$. hirtipes, K.s. AZ $=$ Arizona $K$. sonoriense, and K.s. NM $=$ New Mexico K. sonoriense. Boldface indicates $P \leq .02$.

${ }^{a}$ Includes turtles that completed $55 \mathrm{~d}$ of dehydration and spans the entire trial.

${ }^{\mathrm{b}}$ Includes data from all turtles over the first $30 \mathrm{~d}$ of dehydration (from before trial to midtrial).

${ }^{\mathrm{c}}$ Source of interaction. Following dehydration, K.s. $\cdot_{\mathrm{AZ}}=K \cdot s_{\mathrm{N}_{\mathrm{NM}}}>K . h .=K . f$. Following rehydration, K.h. $>$ K.s. $\cdot_{\mathrm{AZ}}=$ K.s. $\cdot_{\mathrm{NM}}=$ K.f.

${ }^{\mathrm{d}}$ Source of interaction. K.s. $\cdot_{\mathrm{AZ}}$, K.s. $\cdot_{\mathrm{NM}}, K . f .: \mathrm{E}>\mathrm{B}=\mathrm{R} ;$ K.h.: $\mathrm{E}=\mathrm{B}=\mathrm{R}$.

${ }^{\mathrm{e}}$ Source of interaction. K.s. $s_{\mathrm{AZ}}, K . s_{\mathrm{NM}}, K . f .: \mathrm{E}>\mathrm{B}>\mathrm{R} ;$ K.h.: $\mathrm{B}>\mathrm{E}=\mathrm{R}$.

${ }^{\mathrm{f}} \mathrm{Log}$ body mass was included as a covariate in analyses.

\section{Blood Chemistry}

Effect of Estivation and Dehydration. All blood chemistry variables followed a similar general pattern: an increase during dehydration followed by a return to near pretrial levels following rehydration (Table 1; Figs. 4, 5).

Population Differences. Over the first $30 \mathrm{~d}$ of the dehydration trial, plasma osmolality of Arizona Sonoran mud turtles increased faster than for Sonoran mud turtles from New Mexico or for K. flavescens and K. hirtipes (Table 1; Fig. 4). When only group A turtles were considered, population differences in plasma osmolality were muted (Table 1; Fig. 4). Pearson correlation analysis suggested that plasma osmolality was influ- enced by behavior, as well as plasma sodium, BUN, and circulating uric acid concentrations (Table 2).

Sonoran mud turtles from Arizona and New Mexico exhibited similar increases in BUN during dehydration (Fig. 5C); K. flavescens showed the smallest increase, while K. hirtipes was intermediate. Following rehydration, BUN decreased more quickly in both Arizona and New Mexico K. sonoriense than in K. hirtipes or K. flavescens (these differences account for the date $\times$ population interaction [Table 1]).

Plasma potassium (Fig. 5B) and protein (Fig. 5E) concentrations varied similarly among populations. All four populations exhibited comparable levels at the beginning of the trial and following rehydration. At the end of dehydration, concentrations in $K$. sonoriense from Arizona had increased the most, followed by those in K. sonoriense from New Mexico and then 


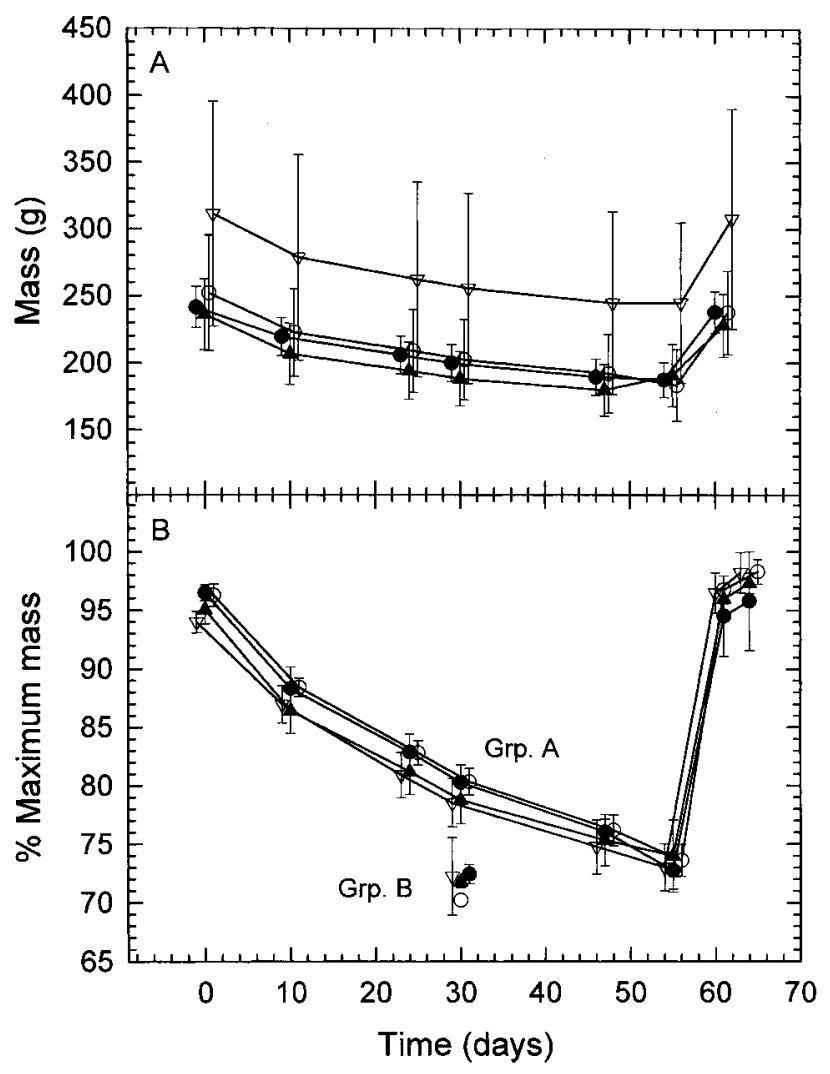

Figure 3. Changes in body mass in mud turtles resulting from dehydration and starvation, followed by rehydration after $55 \mathrm{~d}$. A, Mean body mass of group A turtles in each population. B, Percent of maximum hydrated mass of group A turtles (connected points) and group B turtles before rehydration. Filled circles, Arizona Kinosternon sonoriense; open circles, New Mexico K. sonoriense; filled triangles, Kinosternon flavescens; open inverted triangles, Kinosternon hirtipes. Some points are offset $1-2 \mathrm{~d}$ for clarity.

K. flavescens. Kinosternon hirtipes showed no change in plasma potassium and a slight decrease in protein concentrations.

\section{Evaporative Water Loss}

EWL scaled to body mass (Fig. 6A), with $K$. hirtipes higher than the three other populations (Fig. 7A). Population-specific scaling exponents ranged from 0.249 to 0.324 and did not differ significantly (these exponents were lower than that for the pooled dataset because $K$. hirtipes tended to have higher rates of EWL and larger body size than the three other populations). EWL did not decrease during dehydration (Table 1; Fig. 7A).

\section{Resting Metabolic Rate}

RMR scaled to body mass (Fig. 6B) and metabolic rates measured at the end of estivation were higher than at the beginning
(Table 1). The scaling exponents for individual populations ranged from 0.049 to 1.112 and did not differ significantly. RMR returned to pretrial levels following rehydration (Fig. $7 B$ ). Throughout the trial, mean RMR of $K$. flavescens was consistently lower than those of the three other populations (Table 1; Fig. 7B).

\section{Discussion}

Aquatic animals that experience seasonal fluctuations in water availability may be forced to adopt an amphibious lifestyle (Chilian 1976). Terrestrial activity under these circumstances generally involves migration to other bodies of water or estivation until local water supplies are replenished (MoralesVerdeja and Vogt 1997; Stone 2001). When an animal is terrestrial, retardation of loss of body water (Seidel and Reynolds 1980; Chessman 1984) and tolerance of desiccation and anhomeostasis (Grigg et al. 1986; Peterson 1996) are of primary importance. A reduction in cutaneous permeability and metabolic depression (which decreases water loss from pulmonary surfaces and conserves energy stores) are physiological mechanisms that may minimize water loss (Seidel 1978; Chessman 1984; Kennett and Christian 1994). EWL also can be reduced behaviorally by minimizing activity, reducing operative surface area (Wygoda and Chmura 1990), and selecting estivation sites that maintain relatively low temperatures and high relative humidity.

Our dehydration trials show that, though exposed to similar landscape-scale desertification trends, species and populations of mud turtles in the southwestern United States exhibit an array of strategies to cope with these changes. In general, mud turtles displayed some of the traits predicted to facilitate terrestrial estivation but not others.

The physiological response of turtles to water deprivation evidently was highly dependent on behavior. Mean activity levels of Kinosternon hirtipes and Arizona Kinosternon sonoriense, the two groups in which many turtles reached near-lethal levels of dehydration within $30 \mathrm{~d}$, were higher than those of the New Mexico K. sonoriense and much higher than those of Kinosternon flavescens. However, the few K. hirtipes and K. sonoriense from Arizona that completed the trial (group A) had low activity levels, similar to those of $K$. flavescens (Fig. 2).

Metabolic rate can be influenced by activity. At the end of the trial, New Mexico K. sonoriense had the highest RMR among group A turtles, whereas the other three populations were lower (Fig. $7 B$ ), a pattern similar to that of group A activity (Fig. 2). Metabolic rates of hydrated $K$. flavescens both at the beginning and the end of the trial were lower than those exhibited by the three other populations. That metabolic rates were lowest in hydrated turtles can be interpreted as evidence against metabolic depression during estivation. However, activity levels of turtles while in the metabolic chambers likely affected measurements (thus, measurements may not have been of true 
Table 2: Pearson correlation coefficients of activity, mass, blood variables, evaporative water loss (EWL), and resting metabolic rate (RMR)

\begin{tabular}{|c|c|c|c|c|}
\hline & Activity & $\begin{array}{l}\text { Absolute } \\
\text { Mass (g/d) }\end{array}$ & $\begin{array}{l}\text { Relative Mass } \\
(\% \max / \mathrm{d})\end{array}$ & $\begin{array}{l}\text { Osmolality } \\
(\mathrm{mOsm})\end{array}$ \\
\hline Absolute mass loss $(\mathrm{g} / \mathrm{d})$ & .174 & & & \\
\hline Relative mass loss (\% max/d) & $.663^{\star}$ & $.358^{\star}$ & & \\
\hline Osmolality (mOsm) & $.446^{*}$ & $.674^{*}$ & $.792^{\star}$ & \\
\hline Sodium (mmol/L) & .226 & $.537^{\star}$ & $.703^{\star}$ & $.896^{\star}$ \\
\hline Urea nitrogen $(\mathrm{mg} / \mathrm{dL})$ & $.443^{\star}$ & $.503^{\star}$ & $.615^{\star}$ & $.839^{\star}$ \\
\hline Uric acid $(\mathrm{mg} / \mathrm{dL})$ & .264 & $.597^{\star}$ & $.592^{\star}$ & $.649^{*}$ \\
\hline Potassium (mmol/L) & .233 & -.153 & .048 & -.032 \\
\hline Protein $(\mathrm{g} / \mathrm{dL})$ & .301 & -.080 & .171 & .002 \\
\hline EWL $\left(\mathrm{mL} \mathrm{H}_{2} \mathrm{O} / \mathrm{h}\right)$ & .044 & .096 & .262 & .323 \\
\hline $\mathrm{RMR}(\mathrm{mL} \mathrm{O} / \mathrm{h})$ & .295 & -.050 & .060 & .346 \\
\hline
\end{tabular}

Note. Analyses were performed on a data set of rates of change during dehydration (days 0-55) of group A turtles.

* $P<.05$.

resting metabolic rates). Increased activity is well documented among animals disturbed during estivation (Seidel 1978; Kennett and Christian 1994; Dunlap 1995; Peterson and Stone 2000).

In general, plasma solute concentrations followed a characteristic pattern: dehydration was accompanied by an anhomeostatic increase in plasma concentrations, followed by steep decreases, indicative of dilution, following rehydration. Over the first $30 \mathrm{~d}$ of the trial, Arizona $K$. sonoriense showed the greatest increases in plasma osmolality, followed by $K$. hirtipes; New Mexico K. sonoriense and K. flavescens showed the smallest changes (Fig. 4).

The patterns we observed fit the prediction that the more aquatic populations should show higher rates of increase in osmolality than those that occur in habitats where water availability is sporadic. Differences among populations were obscured when only group A turtles were considered (Fig. 4), but $K$. hirtipes still showed the highest average rates of increase, and $K$. flavescens showed the smallest increases after $55 \mathrm{~d}$ out of water.

In apparent contrast with these results, Peterson and Stone (2000) found that New Mexico K. sonoriense and K. flavescens regulated plasma osmotic concentrations over the first $30 \mathrm{~d}$ of estivation, presumably by reabsorbing bladder water, and then became anhomeostatic only after plasma and bladder urine osmolality became isosmotic. Plasma osmolality was substantially lower at the outset of our study ( 250 vs. $\sim 280 \mathrm{mOsm} /$ $\mathrm{L})$, possibly because the turtles were fasted in deionized water before the dehydration trial. If $300 \mathrm{mOsm} / \mathrm{L}$ is the upper limit of the range of ECF osmolality for hydrated turtles (Peterson and Stone 2000), three of the four populations of group A turtles maintained, on average, normal levels up to the thirtieth day of dehydration, whereas the highly aquatic $K$. hirtipes likely reached this upper limit earlier (Fig. 4). If the pooled data are considered, only $K$. flavescens maintained normal osmolality for $30 \mathrm{~d}$ (Fig. 4).

In the absence of excretory sodium loss, extracellular sodium concentrations should increase in proportion to water loss and thus should be a reliable index of dehydration. With the exception of the two Arizona $K$. sonoriense, changes were as predicted: K. hirtipes exhibited a high rate of increase while out of water, whereas $K$. flavescens and New Mexico K. sonoriense showed similar, lower increases (Fig. 5A).

BUN and circulating uric acid concentrations are influenced by a number of variables. As with other solutes, dehydration has a concentrating effect, resulting in increased levels during

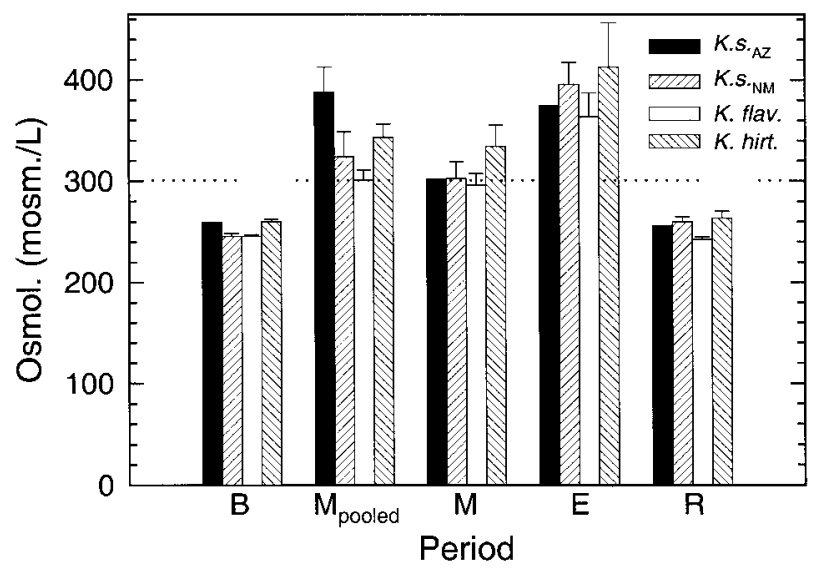

Figure 4. Plasma osmotic concentrations of all mud turtles after $30 \mathrm{~d}$ out of water $\left(M_{\text {pooled }}\right)$ and group A turtles before $(B)$, during $(M)$, and at the end $(E)$ of dehydration and following rehydration $(R)$. Dotted line indicates the upper range of osmotic concentrations of hydrated kinosternids (from Peterson and Stone 2000). 

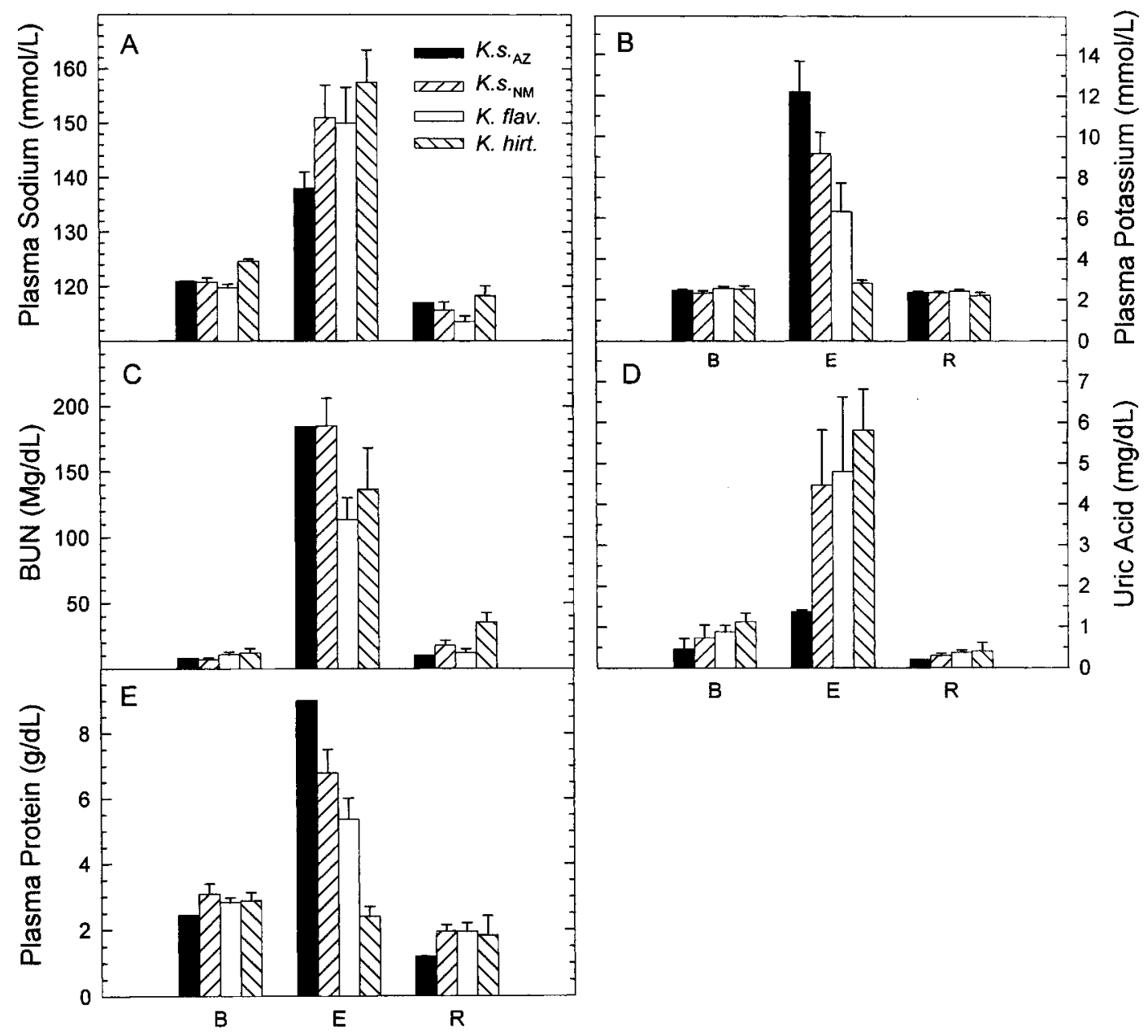

Figure 5. Changes in $(A)$ plasma sodium, $(B)$ plasma potassium, $(C)$ blood urea nitrogen $(B U N),(D)$ uric acid, and $(E)$ protein concentrations before and during water deprivation and following rehydration in mud turtles from four populations.

estivation. These increases are compounded as additional nitrogenous wastes are produced from protein catabolism. Reductions in BUN can be accomplished by maintaining a large bladder reservoir from which water can be reabsorbed to dilute ECF (additionally, urea in solution can be sequestered in the bladder). Uric acid can precipitate out of solution in the urinary bladder, resulting in lower ECF concentrations. Thus, circulating levels are not necessarily indicative of production of nitrogenous wastes (Peterson and Stone 2000). Patterns of increase of blood urea were similar to those described by Peterson and Stone (2000). Both populations of K. sonoriense showed similar high rates of increase in BUN, but increases among $K$. flavescens were lower. The high rates of increase among $K$. sonoriense may be indicative of higher metabolic rates during estivation. Alternatively, $K$. sonoriense may have had lower fat stores than the two other species, forcing them to metabolize protein instead. $K$. flavescens typically have extremely high lipid stores (Chilian 1976; Rose 1980; Long 1985) and were relatively inactive in this study; they also showed the smallest increases in BUN during estivation.

Circulating uric acid levels increased less over the course of the dehydration trial in the two Arizona Sonoran mud turtles than in turtles from the three other populations. Because uric acid is a form of nitrogenous waste that conserves water, the apparent inability to package nitrogen in this form may suggest that this population is less efficient at conserving water. If so, however, it is surprising that $K$. hirtipes, the other highly aquatic group, did not have similarly low uric acid levels.

Concentrations of plasma potassium and protein followed nearly identical patterns and reached extremely high levels in the two Arizona K. sonoriense, compared with published ranges (Fig. 5B, 5E; cf. Seidel and Reynolds 1980; Peterson and Stone 


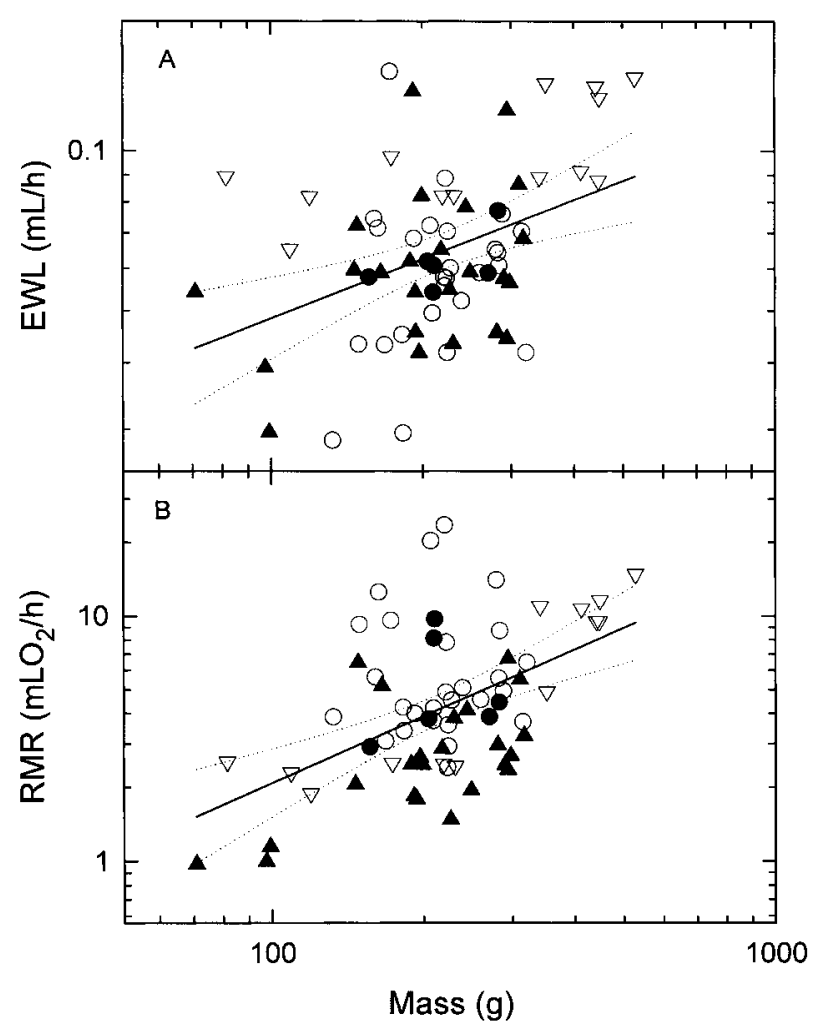

Figure 6. $A$, Rates of evaporative water loss (EWL); $B$, resting metabolic rates (RMR) measured in kinosternid turtles. EWL scaled as $(\mathrm{mL}$ $\left.\mathrm{H}_{2} \mathrm{O} / \mathrm{h}\right)=0.008822(\mathrm{~g})^{0.369}$ and RMR as $\left(\mathrm{mL} \mathrm{O}_{2} / \mathrm{h}\right)=0.031961(\mathrm{~g})^{0.906}$. Axes are logarithmic. Symbols as in Figure 3; dashed lines, 95\% Confidence Intervals.

2000). That these extreme values are mirrored in the two solute groups suggests that some hemolysis may have occurred. It is perplexing that $K$. hirtipes, the other highly aquatic group, exhibited no increases in plasma protein and potassium following dehydration. In view of the large changes in other variables, it seems doubtful that these were tightly regulated; they may indicate lymph contamination (Crawshaw and Holz 1996).

It has been suggested that $K$. flavescens and New Mexico $K$. sonoriense regulate plasma protein concentrations during dehydration (Peterson and Stone 2000), but those in our study increased after $55 \mathrm{~d}$ of dehydration (Table 1). As with plasma osmolality, this difference may reflect the fact that pretrial concentrations were lower in our study and increased to levels comparable with those previously reported in kinosternids (Seidel and Reynolds 1980; Peterson and Stone 2000).

\section{Population Comparisons}

Much of our data suggest that K. flavescens and New Mexico $K$. sonoriense were more tolerant of dry conditions than were
Arizona $K$. sonoriense and $K$. hirtipes. Kinosternon hirtipes showed responses in keeping with their highly aquatic lifestyle. One turtle from this population died during the trial, and four were returned to water after $30 \mathrm{~d}$ (those that completed the trial probably did so by virtue of their large size and low activity). Mean activity levels were high, and plasma osmotic concentrations and plasma sodium reached the highest levels of the four populations after $55 \mathrm{~d}$ of dehydration. Finally, even after accounting for their larger mass, $K$. hirtipes displayed rates of EWL substantially higher than the other populations studied.

Kinosternon flavescens and the New Mexico K. sonoriense responded very similarly to dry conditions. Both maintained low levels of activity ( $K$. flavescens was the lowest of the four populations), had the smallest increases in plasma osmolality, and exhibited nearly identical changes in levels of circulating uric acid. These conclusions are consistent with those of Peterson and Stone (2000).

Comparisons of conspecific populations can be an instructive approach to evolutionary physiology (Garland and Adolph 1991). Clearly, the two populations of $K$. sonoriense differed in their responses to droughtlike conditions. Turtles from the New

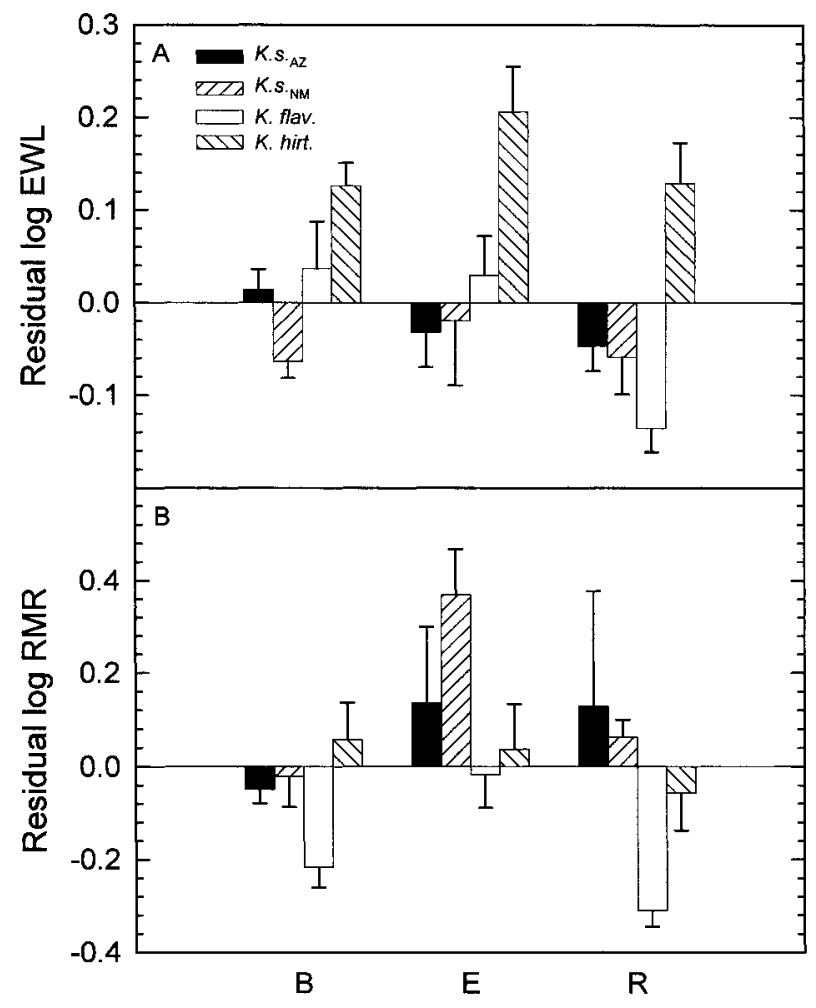

Figure 7. Changes in $(A)$ evaporative water loss (EWL) and $(B)$ resting metabolic rate (RMR) in kinosternid turtles at the beginning $(B)$ and end $(E)$ of water and food deprivation and following rehydration $(R)$. Residuals from log-log regressions on mass (shown in Fig. 6) are plotted to correct for intra- and interpopulational differences in body size. 
Mexico population had lower activity levels, slower increases in plasma osmolality (when all turtles were included over the first $30 \mathrm{~d}$ of the trial), and higher concentrations of uric acid. The K. sonoriense from Arizona faired poorly: one turtle died after just $25 \mathrm{~d}$ out of water, and another seven had to be rehydrated after $30 \mathrm{~d}$ (compared with just one from the New Mexico population). The two Arizona turtles that completed the trial performed well in many respects, but their responses were atypical of the population. The differences observed between the two populations of $K$. sonoriense parallel local differences in water availability. The Chiricahua Mountains in southeastern Arizona receive more precipitation and have more spring-fed streams than do the Peloncillo Mountains in New Mexico, and as recently as 10,000 yr ago, the Chiricahua Mountains lay on the eastern shore of Lake Cochise (Long 1966).

Some of the variables measured support the notion of coadaptation of behavioral and physiological components of drought survival strategies. Such coadaptation (Hertz et al. 1988; Huey et al. 1989; Bauwens et al. 1995) may result from population-level adaptation to local differences in water availability. Kinosternon hirtipes appeared to be behaviorally and physiologically constrained to aquatic habitats; individuals from this population exhibited relatively high activity levels during dehydration, and rates of EWL were substantially greater than the other three populations studied. Conversely, K. flavescens had very low activity scores coupled with low metabolic rates, in keeping with its proclivity for terrestrial dormancy.

Most of our evidence supports the alternative possibility, that the physiological differences observed between populations were simply consequences of differences in behavior. There were strong correlations between individual activity levels and relative mass loss and changes in plasma osmotic concentrations during the trial (Table 2), whereas patterns of change in these variables were not attributable to population differences (Table 1). That estivation has a strong behavioral component is beyond doubt; the question of whether physiological adaptations for increased drought tolerance exist remains open.

\section{Acknowledgments}

We thank R. Kazmaier, E. Ligon, C. Perry, and W. Webb for assistance in collecting turtles and E. Hellgren, P. Stone, and three anonymous reviewers for their comments on this manuscript. Financial support was provided by a Theodore Roosevelt Memorial Grant from the American Museum of Natural History and the Oklahoma State University Department of Zoology Wilhme Award. Turtles were collected under Arizona Game and Fish permit SP914310, New Mexico Department of Game and Fish permit 2905, and Texas Parks and Wildlife permit SPR0290-015.

\section{Literature Cited}

Bauwens D., T. Garland, Jr., A.M. Castilla, and R. Van Damme. 1995. Evolution of sprint speed in lacertid lizards: morphological, physiological, and behavioral covariation. Evolution 49:848-863.

Chessman B.C. 1984. Evaporative water loss from three southeastern Australian species of freshwater turtle. Aust J Zool 32:649-655.

Chilian W.M. 1976. Physiological Strategies of Dormancy of Kinosternon flavescens. MS thesis. Texas Tech University, Lubbock.

Christian K., B. Green, and R. Kennett. 1996. Some physiological consequences of estivation by freshwater crocodiles, Crocodylus johnstoni. J Herpetol 30:1-9.

Crawshaw G.J. and P. Holz. 1996. Comparison of plasma biochemical values in blood and blood-lymph mixtures from red-eared sliders, Trachemys scripta elegans. Assoc Reptile Amphib Vet 6:7-9.

Dunlap K.D. 1995. Hormonal and behavioral responses to food and water deprivation in a lizard (Sceloporus occidentalis): implications for assessing stress in a natural population. J Herpetol 29:345-351.

Ernst C.H. 1968. Evaporative water-loss relationships of turtles. J Herpetol 2:159-161.

Ernst C.H., R.W. Barbour, and J.E. Lovich. 1994. Turtles of the United States and Canada. Smithsonian Institution, Washington, D.C.

Fredrickson E., K.M. Havstad, R. Estell, and P. Hyder. 1998. Perspectives on desertification: south-western United States. J Arid Environ 39:191-207.

Garland T., Jr., and S.C. Adolph. 1991. Physiological differentiation of vertebrate populations. Annu Rev Ecol Syst 22: 193-228.

Grigg G.C., K. Johansen, P. Harlow, L.A. Beard, and L.E. Taplin. 1986. Facultative estivation in a tropical freshwater turtle Chelodina rugosa. Comp Biochem Physiol 83:321-323.

Hertz P.E., R.B. Huey, and T. Garland, Jr. 1988. Time budgets, thermoregulation, and maximal locomotor performance: are reptiles Olympians or boy scouts? Am Zool 28:927-938.

Huey R.B., P.H. Niewiarowski, J. Kaufmann, and J.C. Herron. 1989. Thermal biology of nocturnal ectotherms: is sprint performance of geckos maximal at low body temperatures? Physiol Zool 62:488-504.

Hulse A.C. 1974. An Autecological Study of Kinosternon sonoriense Leconte (Chelonia: Kinosternidae). PhD diss. Arizona State University.

Iverson J.B. 1989. The Arizona mud turtle, Kinosternon flavescens arizonense (Kinosternidae), in Arizona and Sonora. Southwest Nat 34:356-368.

1992. A Revised Checklist with Range Maps of the Turtles of the World. Privately printed, Richmond, Ind. Iverson J.B., E.L. Barthelmess, G.R. Smith, and C.E. deRivera. 
1991. Growth and reproduction of the mud turtle Kinosternon hirtipes in Chihuahua, Mexico. J Herpetol 25:64-72.

Kennett R. and K. Christian. 1994. Metabolic depression in estivating long-neck turtles (Chelodina rugosa). Physiol Zool 67:1087-1102.

Kuchling G. 1999. The Reproductive Biology of the Chelonia. Springer, New York.

Ligon D.B. 2001. Coadaptation of Physiology and Behavior: Variation in Estivation among Mud Turtles (Kinosternon spp.). MS thesis. Oklahoma State University, Stillwater.

Long A. 1966. Late Pleistocene and Recent Chronologies of Playa Lakes in Arizona and New Mexico. PhD diss. University of Arizona, Tucson.

Long D.R. 1985. Lipid utilization during reproduction in female Kinosternon flavescens. Herpetologica 41:58-65.

Mahmoud I.Y. 1969. Comparative ecology of the kinosternid turtles of Oklahoma. Southwest Nat 14:31-66.

Mautz W.J. 1982. Patterns of evaporative water loss. Pp. 443-481 in C. Gans and F.H. Pough, eds. Biology of the Reptilia. Vol. 12. Physiology C, Physiological Ecology. Academic Press, New York.

Minnich J.E. 1979. Reptiles. Pp. 391-641 in G.M.O. Maloiy, ed. Comparative Physiology of Osmoregulation in Animals. Vol. 1. Academic Press, New York.

Morales-Verdeja S.A. and R.C. Vogt. 1997. Terrestrial movements in relation to aestivation and the annual reproductive cycle of Kinosternon leucostomum. Copeia 1997:123-130.

Peterson C.C. 1990. Paradoxically low metabolic rate of the diurnal gecko Rhoptropus afer. Copeia 1990:233-237.

- 1996. Anhomeostasis: seasonal water and solute relations in two populations of the desert tortoise (Gopherus agassizii) during chronic drought. Physiol Zool 69: 1324-1358.

Peterson C.C. and D. Greenshields. 2001. Negative test for cloacal drinking in a semi-aquatic turtle (Trachemys scripta), with comments on the functions of cloacal bursae. J Exp Zool 290:247-254.

Peterson C.C. and P.A. Stone. 2000. Physiological capacity for estivation of the Sonoran mud turtle, Kinosternon sonoriense. Copeia 2000:684-700.

Rose F.L. 1980. Turtles in arid and semi-arid regions. Bull Ecol Soc Am 61:89.

Schmidt R.H., Jr. 1979. A climatic delineation of the "real" Chihuahuan desert. J Arid Environ 2:243-250.

Seidel M.E. 1978. Terrestrial dormancy in the turtle Kinosternon flavescens: respiratory metabolism and dehydration. Comp Biochem Physiol 61:1-4.

Seidel M.E. and S.L. Reynolds. 1980. Aspects of evaporative water loss in the mud turtles Kinosternon hirtipes and $\mathrm{Ki}$ nosternon flavescens. Comp Biochem Physiol 67:593-598.

Stone P.A. 2001. Movements and demography of the Sonoran mud turtle, Kinosternon sonoriense. Southwest Nat 46:41-53.

Van Devender T.R., R.S. Thompson, and J.L. Betancourt. 1987. Vegetation history of the deserts of the southwestern North America: the nature and timing of the Late WisconsinHolocene transition. In W.F. Ruddiman and H.E. Wright, Jr., eds. North America and Adjacent Oceans during the Last Glaciation. The Geology of North America, vol. K-3. Geological Society of America, Boulder, Colo.

van Loben Sels R.C., J.D. Congdon, and J.T. Austin. 1997. Life history and ecology of the Sonoran mud turtle (Kinosternon sonoriense) in southwestern Arizona: a preliminary report. Chelonian Conserv Biol 2:338-344.

Vleck D. 1987. Measurement of $\mathrm{O}_{2}$ consumption, $\mathrm{CO}_{2}$ production, and water vapor production in a closed system. J Appl Physiol 62:2103-2106.

Wygoda M.L. and C.M. Chmura. 1990. Effects of shell closure on water loss in the Sonoran mud turtle, Kinosternon sonoriense. Southwest Nat 35:228-229. 